\title{
RA?
}

O ESPACO GEOGRÁFICO EM ANÁL.ISE

\section{DINÂMICAS TERRITORIAIS DOS PRINCIPAIS NODAIS SULISTAS DO TRANSPORTE RODOVIÁRIO DE CARGA}

\section{TERRITORIAL DYNAMICS OF THE MAIN SOUTHERN NODAL ROAD FREIGHT}

\author{
Daniel Monteiro Huertas \\ Universidade Federal de São Paulo - UNIFESP \\ São Paulo, SP, Brasil \\ e-mail: dmhuertas@unifesp.br
}

\section{Recebido em: 25/05/2015}

Aceito em: 20/05/2016

\section{Resumo}

Em análise estruturada a partir da teoria do espaço geográfico, este artigo tem como objetivo demonstrar as peculiaridades e dinâmicas territoriais que corroboram a inserção do polígono gaúcho (Porto Alegre-Caxias do SulLajeado-Santa Cruz do Sul) e dos eixos paranaense (Ponta Grossa-CuritibaParanaguá) e catarinense (Blumenau-Joinville-Itajaí-Florianópolis-Criciúma) como centralidades da rede geográfica do transporte rodoviário de carga, cuja configuração territorial é composta por linhas e nodais que em seu conjunto expressam a organização e estruturação desta atividade na formação socioespacial brasileira e evidenciam um processo de seletividade espacial que privilegiou certos pontos e áreas em detrimento de outros, demarcado pela concentração e atuação de seus agentes. Conclui-se, mediante ampla investigação empírica, que os três Estados sulistas formam um denso corredor rodoviário longitudinal de cerca de $700 \mathrm{~km}$ entre Curitiba e Porto Alegre, seja pelo litoral (BRs 376, 101 e 290), seja pelo interior (BR-116), de grande importância para 0 conjunto do país, principalmente como centros consumidores relevantes e de produção industrial diversificada. Fluxos intrarregionais densos, entre capitais e destas com o interior de seus respectivos Estados; maior equilíbrio de frete-retorno; forte relação com São Paulo e presença significativa de caminhoneiros autônomos são outras características do conjunto de nodais em questão.

Palavras-chave: circulação; centralidade; seletividade espacial.

\section{Abstract}

In structured analysis from the theory of geographical space, this article aims to demonstrate the peculiarities and territorial dynamics that confirmed the 
insertion of the gaúcho polygon (Porto Alegre-Caxias do Sul-Lajeado-Santa Cruz do Sul) and the paranaense (Ponta Grossa-Curitiba-Paranaguá) and catarinense (Joinville-Itajaí-Florianópolis-Criciúma) axes like centralities of road freight transport geographical network, whose territorial configuration consists of nodals and lines which together express the organization and structuring of this activity in the Brazilian social and spatial formation and show a selective spatial process that privileged certain points and areas in detriment of others, marked by concentration and action of its agents. We conclude, by ample empirical research, the three Southern states form a dense longitudinal road corridor of about $700 \mathrm{~km}$ between Curitiba and Porto Alegre, is the coast (BRs 376, 101 and 290), or the inside (BR-116), of great importance for the whole country, mainly as relevant consumer centers and diversified industrial production. Dense intra-regional flows of capital cities and those with the interior of their respective States; more balanced freight-return; strong relationship with São Paulo and significant presence of independent truckers are other set of nodal characteristics in question.

Key words: circulation; centrality; spatial selectivity.

\section{INTRODUÇÃO}

Em análise estruturada a partir da teoria do espaço geográfico, o uso do território brasileiro pela ótica do transporte rodoviário de carga (TRC) - que movimenta cerca de $60 \%$ de toda a carga do país, segundo a Agência Nacional de Transporte Terrestre (ANTT) - pode ser evidenciado por um processo de seletividade espacial que privilegiou certos pontos e áreas em detrimento de outros. Como o transporte também pode ser considerado um dos fatores locacionais por conta das possibilidades que oferece para a redução de custos (THOMSON, 1976), os agentes dos circuitos espaciais de produção (SANTOS, 1988) buscam atuar em sintonia com os agentes do TRC - empresas transportadoras de carga (ETC) e transportadores autônomos de carga (TAC), segundo a lei 11.442/07, que enquadrou o TRC como aquele "realizado em vias públicas, no território nacional, por conta de terceiros e mediante remuneração", cuja atividade econômica "é de natureza comercial, exercida por pessoa física ou jurídica em regime de livre concorrência”.

As solidariedades organizacionais geradas estimulam e facilitam a localização dos agentes em pontos privilegiados do território, geralmente nodais situados em tramos estratégicos da rede rodoviária e da rede urbana. 
Afinal, como já nos disse Milton Santos (2004) em sua análise do imperativo da fluidez, não basta produzir; é indispensável pôr a produção em movimento.

Levando-se em consideração que o TRC cria uma topologia própria, cuja configuração territorial é composta por linhas e nodais que em seu conjunto modelam uma rede geográfica capaz de expressar a sua organização e estruturação na formação socioespacial brasileira (HUERTAS, 2013), este artigo tem como objetivo demonstrar as peculiaridades e dinâmicas territoriais que corroboram a inserção do polígono gaúcho (Porto Alegre-Caxias do SulLajeado-Santa Cruz do Sul) e dos eixos paranaense (Ponta Grossa-CuritibaParanaguá) e catarinense (Joinville-Itajaí-Florianópolis-Criciúma) como centralidades da rede em questão.

Trata-se de um conjunto nodal enlaçado pelas BRs 376 (CuritibaGaruva/SC), 101 (Garuva-Osório/RS) e 290 (Osório-Porto Alegre), ao longo da costa, e pela BR-116 (Curitiba-Lages/SC-Caxias do Sul/RS-Porto Alegre), pelo interior, com predominância de nodais secundários polifuncionais, diretamente atrelados à logística de atividades industriais. Este conjunto registra 155 matrizes de empresas transportadoras e 1.005 filiais espalhadas por 97 cidades, segundo a pesquisa realizada.

\section{MATERIAIS E MÉTODO}

O ponto analítico central proposto, em termos de circulação, é a configuração de uma rede geográfica do transporte rodoviário de carga reveladora do uso do território. Roberto Lobato Corrêa (1997, p.306) demonstra como as redes geográficas são construções sociais "historicamente contextualizadas, constituindo-se em parte integrante do longo e cada vez mais complexo processo de organização espacial", e locus da efetivação das interações espacias "a partir dos atributos das localizações e das possibilidades reais de se articularem entre si".

Organizamos o estudo da rede geográfica em questão para o território brasileiro levando em consideração funcionalidades, hierarquias e polarizações, atributos que em seu conjunto mais amplo denotam tanto a dissociação quanto a conectividade geográfica dos lugares e a seletividade 
espacial. Acreditamos, assim, que este caminho metodológico proporcione uma leitura bastante interessante no que diz respeito ao uso do território, evidenciando com mais força a hierarquia dos lugares gerada pela circulação diferenciada do excedente (ARROYO, 2005).

\section{RESULTADOS E DISCUSSÃO}

Os nodais ajudam a explicar a rede geográfica e são tidos, portanto, como a expressão máxima da seletividade espacial do transporte rodoviário de carga pela densidade de fixos e pela frequência, qualidade e intensidade dos fluxos. Do ponto de vista operacional, apenas nos nodais registra-se a possibilidade de implementar uma distribuição territorial completa das mercadorias em fluxos T1 (escala nacional-T1/A, macrorregional-T1/B e mesorregional-T1/C) e T2 (escala microrregional-T2/D, intraurbana metropolitana-T2/E e intraurbana intermediária-T2/F), cujos movimentos demarcam a escala de atuação de empresas transportadoras e motoristas autônomos (HUERTAS, 2013).

Além disso, são os principais pontos de origem e destino de todo o movimento de carga lotação (ou carga fechada, com carregamento num único ponto e entrega num único ponto) empreendido no país, embora não haja estatísticas que possam comprovar este fenômeno. Os nodais reúnem uma série de atributos geográficos - revendas de caminhões, concentração de agentes e suas respectivas representações sindicais e de fixos logísticos - que Ihes conferem uma centralidade, comprovando territorialmente a densidade e escala de objetos ligados direta ou indiretamente ao TRC, o que de certa forma ajuda a corroborar a hierarquia dos lugares no que diz respeito à circulação.

Logo de imediato é importante salientar algumas considerações gerais a respeito dos nodais. Em todos os casos ocorre uma espécie de "nexo territorial", consubstanciado pela conjugação entre a capacidade dos agentes instalados em condicionar arranjos territoriais em todas as escalas (fluxos T1 e T2), a formação do valor do frete e as amplas condições de fluidez territorial, o que significa situação locacional em trechos privilegiados da rede rodoviária nacional e acesso facilitado a portos, ferrovias, hidrovias e aeroportos. 
Corresponde, portanto, às interações espaciais que reforçam a interconectividade entre os agentes do transporte rodoviário de carga e destes com os agentes dos circuitos espaciais de produção.

Esta condição única no território nacional, portadora de verticalidades que criam e recriam solidariedades organizacionais, revela a estrutura e organização socioeconômica e política superior dos nodais em relação ao TRC. “...as metrópoles econômicas nacionais usufruem de posição estratégica na moderna rede de transporte. Isso Ihes assegura relações mais fáceis com o resto do território, aumentando assim sua capacidade de competição" (SANTOS, 2008, p.309).

As características acima denotam a localização dos fixos mais estratégicos em termos de expedição, transferência e consolidação de carga e capacidade de armazenagem, além da presença de pessoal mais qualificado para o desenvolvimento das tarefas administrativas e operacionais que envolvem o TRC. Segundo estudo do Geipot citado por Silva Junior (2004), 1/3 do total da frota de caminhões do país opera em percursos rodoviários (fluxos T1 e T2/D), viagens de média e longa distância com custos de transferência representativos por causa dos fixos. Soma-se a isso o fato de que nas operações de coleta e entrega (fluxos T2/E e T2/F), cujo volume também está bastante concentrado nos nodais, os custos fixos dos veículos pefazem mais de $60 \%$ do total dos custos operacionais.

Entende-se assim que os nodais concentram boa parte dos custos totais do TRC, elemento fundamental para o planejamento estratégico do circuito superior. No plano político, concentram grande parte das instituições responsáveis pela representação de suas categorias, com capacidade de debater e direcionar os assuntos normativos correlatos à atividade, com forte influência na regulamentação do setor. "Em regra geral, os atores que possuem os nós detêm o controle dos dispositivos: é nos polos que se efetua o tratamento estatístico dos objetos, garantia da qualidade da prestação global, que se organiza a cadeia de entrega com suas subcontratações hierárquicas" (SAVY, 1993, p.216; tradução livre). 
De modo geral, observa-se que todas as características supracitadas são típicas de cidades com maiores níveis de especialização e diversificação econômica, em hierarquias superiores na rede urbana brasileira, cuja concentração de variáveis diretamente relacionadas ao TRC proporciona uma sinergia territorial entre os agentes e acaba reforçando o poder de polarização e centralidade das aglomerações urbanas onde se localizam - geralmente no entorno de grandes cidades, nós de circulação e pontos de convergência das vias de comunicação com interpentração de circulação geral e local (CLOZIER, 1963).

No processo de urbanização, há [...] uma tendência crescente à diferenciação e à especialização, acompanhada de uma maior divisão interurbana do trabalho, e atrelada diretamente às possibilidades de articulação que a dinâmica da circulação promove (ARROYO, 2006, p.76).

De certa forma o nodal está vinculado a uma economia complexa, "caracterizada, e viabilizada, por uma complexa divisão territorial do trabalho", e associado à rede urbana, "cujos centros estão fortemente integrados entre si" (CÔRREA, 2006, p.306). Mas os nodais também revelam situações intermediárias, que ajudam a compreender com mais profundidade a correlação de forças entre os agentes do transporte rodoviário de carga e os níveis inferiores da rede urbana brasileira.

\footnotetext{
Esses sistemas de tessituras, de nós e de redes organizadas hierarquicamente permitem assegurar o controle sobre aquilo que ser distribuído, alocado e/ou possuído. Permitem ainda impor e manter uma ou várias ordens. Enfim, permitem realizar a integração e a coesão dos territórios. Esses sistemas constituem o invólucro no qual se originam as relações de poder (RAFFESTIN, 1993, p.151).
}

Além disso, se a circulação diferenciada do excedente cria uma hierarquia entre os lugares (ARROYO, 2005), os nodais podem ser analisados, também, pelas grandes possibilidades que oferecem para reter boa parte deste 
excedente, porque "sem a circulação de bens não há circulação do excedente" (SANTOS, 2003, p.144).

São nos nodais que se materializam no território as maiores possibilidades daquelas metamorfoses M-D e D-M explicadas por Marx, fenômeno que intensifica o que ele chamou de "processo adicional da produção da indústria de transportes", visível na densidade do trinômio proposto. Além disso, são nos nodais que a aplicação da lei geral da produção de mercadorias, que também "se aplica à indústria de transportes como a qualquer outra" (MARX, 2011, p.167), adquire a sua condição plena, pois a concentração de agentes da circulação nesses nexos territoriais favorece a diminuição dos custos de transporte.

Ademais, valendo-se ainda da teoria marxista, são nos nodais que residem as maiores possibilidades de balanceamento entre o tempo de compra e de venda - cuja soma define o tempo de circulação do capital, uma das frações do ciclo de circulação do capital como um todo -, pois "o afastamento do mercado prolonga o tempo em que o capital fica prisioneiro da forma de capital-mercadoria, retarda diretamente o retorno do dinheiro, por conseguinte a transformação do capital-dinheiro em capital-produtivo" (MARX, 2011, p.290).

O autor explica que a repartição do retorno do dinheiro "por maior número de períodos sucessivos encurta o tempo global de circulação e, por conseguinte, a rotação" (MARX, 2011, p.287), condição possível, para o caso específico da formação socioespacial brasileira, pelo entrelaçamento territorial proporcionado pelos nodais, que amarram os principais mercados produtores e consumidores de um país com dimensões continentais e desequilíbrios regionais.

Nos nodais observa-se um melhor desenvolvimento dos meios de transporte, fato que "aumenta a velocidade do movimento no espaço e assim reduz-se no tempo a distância geográfica" (MARX, 2011, p.286). Esta redução absoluta do tempo de viagem das mercadorias, embora permaneça a diferença relativa, só é possível pela maior frequência com que funcionam os agentes da circulação nos nodais, além da amplitude de suas escalas de atuação no território nacional. 
$\mathrm{Na}$ divisão territorial do trabalho do período atual, os nodais do transporte rodoviário de carga, locus de alta produtividade espacial ou subsistemas logísticos que facilitam a fluidez e hierarquizam o território pelos seus requisitos técnico-organizacionais (SANTOS, 2004), proporcionam um movimento convergente de articulação do todo nacional, embora o espaço se torne "mais articulado às relações funcionais, e mais desarticulado quanto ao comando local das ações que nele se exercem" (SANTOS, 2005, p.49). A análise geográfica, portanto, parte do princípio de que o espaço também se impõe por meio das condições que oferece para a circulação.

\subsection{Recortes espaciais e topologia dos nodais}

O recorte espacial dos nodais, como proposta metodológica, considera a relação entre quantidade e contiguidade de matrizes e seus fixos correlatos (filiais, centros de operação, pontos de apoio, centros de distribuição, agências, centros de envio e franquias) de uma relação de 800 empresas transportadoras levantadas em pesquisa de elaboração própria como o indicador que esclarece os arranjos territoriais do TRC ao longo da formação socioespacial brasileira, relacionando-o com a rede rodoviária nacional e a rede urbana (HUERTAS, 2013). A pesquisa apontou 7.401 fixos em 1.087 cidades de todas as Unidades da Federação, sendo que, respectivamente, 6.936 (93,71\%) e 695 (63,93\%) estão situados nos nodais, classificados em quatro níveis:

(i) Primário: "polígono paulista", força polarizadora única no território nacional que acolhe 304 matrizes (38\% do total), com 1.618 fixos $(21,8 \%)$ alocados em 144 cidades $(13,2 \%)$, e responsável pela determinação das rotas, prazos de tempo de trânsito de carga e valor do frete de boa parte do país;

(ii) Secundários polifuncionais: aqueles em que os circuitos espaciais de produção industrial são o suporte das atividades geradoras de carga, tornando o seu tecido econômico mais diversificado e complexo; 
(iii) Secundários monofuncionais: aqueles cuja tipologia pode estar relacionada à especialização produtiva (circuitos espaciais de produção petrolífera e agropecuária), à situação geográfica (acesso fronteiriço ao Mercosul) ou à logística do comércio atacadista e distribuidor e da produção salineira;

(iv) Terciários (relês regionais): centros responsáveis por fluxos T2/D (rotas microrregionais) e T2/F (cidades intermediárias).

A configuração de um nodal em cidades que dispõem de pelo menos três fixos e/ou de uma matriz é uma condição restrita ao nodal terciário, o mais baixo da classificação proposta. Os dois níveis superiores, ou nodais primários e secundários, somente ocorrem em cidades com seis ou mais fixos e pelo menos uma matriz, sendo que a sua composição completa, no caso de eixos e polígonos, deve incluir também todas as cidades adjacentes aos seus eixos rodoviários estruturantes que contam com pelo menos um fixo.

De certa forma, esta proposta metodológica constrói-se a partir do circuito superior do transporte rodoviário de carga (grandes e médias transportadoras), embora os circuitos superior marginal e inferior (pequenas transportadoras e motoristas autônomos) estejam diretamente atrelados e subordinados, espacialmente falando, aos desígnios técnico-operacionais e informacionais dos agentes hegemônicos.

A pesquisa desenvolvida ainda indica que as empresas de transporte rodoviário de carga pensam o Brasil no sentido longitudinal (norte-sul), até uma faixa de cerca de $200 \mathrm{~km}$ do litoral no Nordeste e de $600 \mathrm{~km}$ na Região Concentrada - obviamente onde se concentram os seus principais centros produtores e consumidores. Fora dessa zona, apenas alguns nodais e relês aparecem como centralidades associadas ao TRC no Brasil contemporâneo, fato que de certa forma demonstra a leitura territorial de "estilo christalliana" exercida pelo mercado.

Isso também significa que, de forma geral, o atendimento ao extenso interior do país é feito de modo mais otimizado e lento, pois o crescimento das distâncias é proporcional à diminuição dos mercados (ou seja, menos carga 
para transportar), situação que requer do transportador ajustes, adaptações e parcerias. A pesquisa também demonstra que a distribuição espacial de nodais ao longo do território nacional pode ser um dos indicadores das crônicas e históricas desigualdades regionais, principal característica da formação socioespacial brasileira.

\subsection{O enlace rodoviário Paraná-Santa Catarina-Rio Grande do Sul}

O eixo paranaense (DIAGRAMA 1) justifica-se por uma série de motivos, incluindo o elevado número de empresas transportadoras locais e de outros Estados, a força do motorista carreteiro em Ponta Grossa, a importância do porto de Paranaguá e a proximidade com São Paulo como grande vantagem comparativa, tornando-se um nó redistribuidor da Região Sul e também dos fluxos para o Mercosul e do agronegócio do Centro-Oeste. A própria configuração territorial da rede rodoviária do Estado colabora na definição do eixo nodal em questão, pois o chamado "anel de integração" enlaça as porções norte (Londrina) e oeste (Cascavel) do Paraná entre elas e com a Região Metropolitana de Curitiba (RMC) e litoral. 


\section{DIAGRAMA 1. Configuração territorial do eixo paranaense}

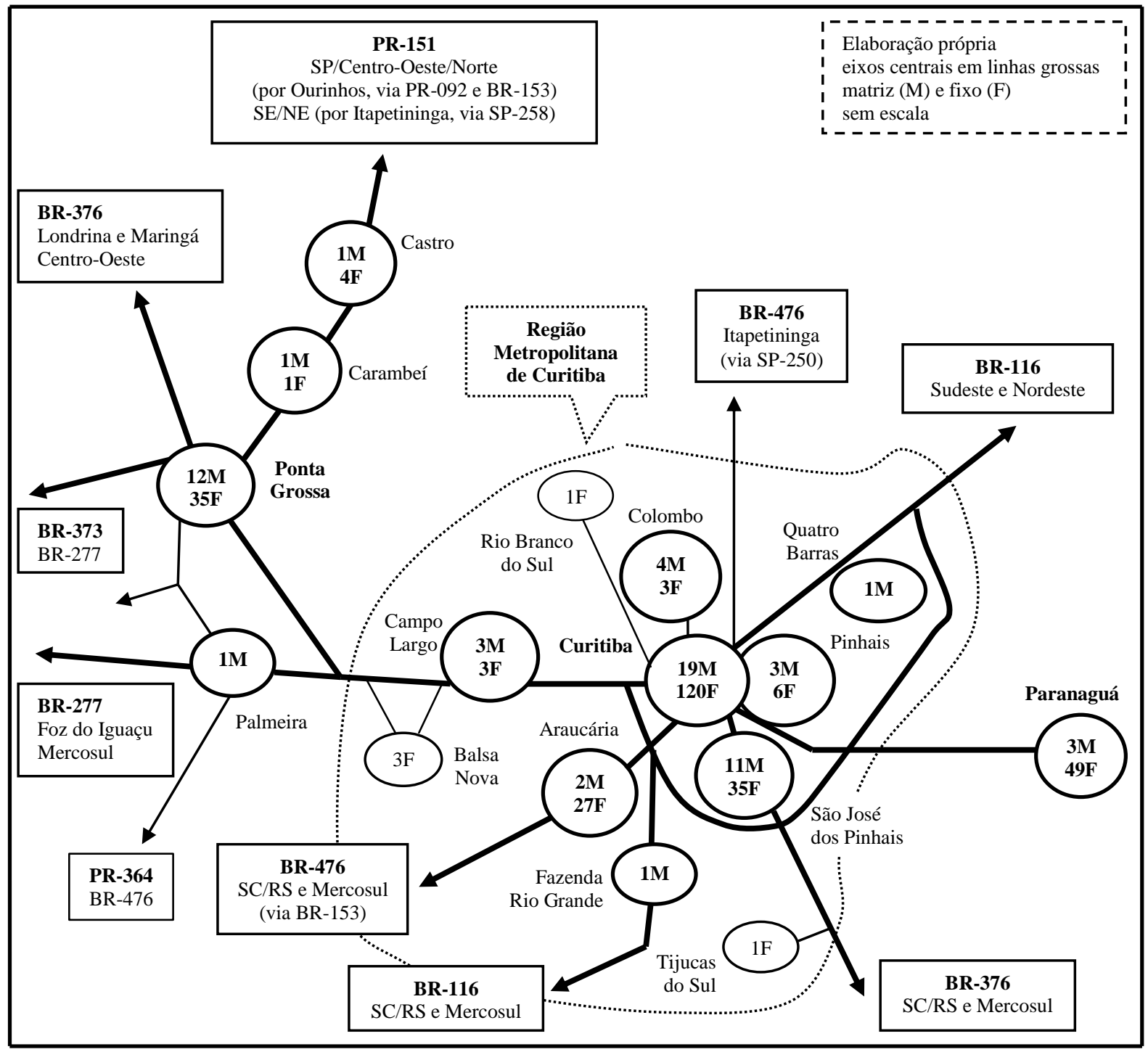

A principal concentração de ETCs locais está na RMC, na qual se entrelaça um rosário de caminhos para todas as direções acessíveis pelo anel de contorno da capital. Curitiba é sede de uma unidade Sest/Senat, um Clia, um porto seco e das duas recém-empresas criadas com foco na intermodalidade rodoferroviária: a Ritmo Logística é resultado da fusão das unidades de transporte rodoviário da América Latina Logística (ALL) e Ouro Verde, com foco no agronegócio; e a Brado Logística, controlada pela ALL $(80 \%)$ e pela estadunidense Standard (20\%), é a divisão de operação de contêiner da ALL. 
Estrela do Oriente e IBL operam fluxos T1/B de insumos e carga geral com São Paulo, e a Sulista é especializada no transporte de insumos para a indústria automobilística, com filiais em São Paulo e Rio Grande do Sul. A Cargolift, de transporte de contêiner (cerca de 2 mil por mês), é uma das maiores do Estado, com 14 filiais (SP/6, RS/3, PR/3, SC/1 e MG/1). A Rodolatina é especializada no segmento de cimento e calcário, com filiais em todas as regiões do país (três em Minas, polo siderúrgico); e a Transemba opera apenas no segmento de papel e celulose, com filiais no Sul, São Paulo e Minas.

Ainda na capital, a Trans-iguaçu, de 1967, é uma das mais antigas, operando insumos e carga geral em fluxos T1 para o Sul e Sudeste, mesma situação de Transgires, com filiais em Santa Catarina, São Paulo, Minas Gerais, Brasília, Goiás e Pernambuco, e Santa Felicidade, com filiais no Sudeste e Goiás. A Rodofácil trabalha com carga geral e encomendas; Kasul com carga especial e TIC com combustível e granéis líquidos químicos. Transválter, Campos Dourados e Rodobrás transportam carga geral (a segunda mantém 33 filiais entre os Estados do Sul e São Paulo), e a Budel trabalha com carga química e máquinas do Rio Grande do Sul à Bahia.

São José dos Pinhais, maior cidade metropolitana depois de Curitiba e berço da indústria automobilística paranaense (Volvo, Renault/Nissan e VW/Audi), é um polo diversificado de ETCs. A BBM opera insumo, carga geral e carga florestal em fluxos T1 nas regiões Sul e Sudeste; mesma situação da Sibra (à exceção da carga florestal). A Malta roda entre São Paulo e Minas com carga geral e insumos, e a Diamente entre São Paulo e Espírito Santo, inclusive contêiner.

A Jrotaner transporta carga especial entre Santa Catarina e São Paulo; Axon e Master trabalham com insumo e a Rodoac carrega granel sólido pelo Sudeste. Carga frigorificada é a especialidade da Transfrios, com filial em São Paulo, e a Kraft opera contêiner, carga especial e geral entre Paranaguá e Navegantes (SC). A Cooperlog roda com contêiner e carga geral até Paranaguá.

Em Araucária, sede de um terminal de carregamento de combustível, estão a BBC, que opera carga geral, contêiner e insumo entre o Rio Grande do Sul e São Paulo; e a Transdiário, de carga geral e insumo. Carga geral e insumo 
são o foco da Transdotti, de Colombo, com três filiais em São Paulo e uma em Santa Catarina; da Rodomodal, de Quatro Barras, que roda para São Paulo e Bahia; da Carrasco, de Colombo; e da Transmaroni, de Pinhais. Nesta última cidade está a Cargosoft, uma das maiores do Estado, que opera apenas insumo industrial do Rio Grande do Sul a Goiás, além da Tespal, de encomendas.

Em Campo Largo, a Quinta carrega insumo e combustível; a Gobor opera carga geral, frigorificada e granel sólido para São Paulo, Mato Grosso, Rondônia e Acre; e a Transpiso trabalha com material de construção. Em Fazenda Rio Grande, a Transberdusco opera carga química. Colombo também é sede da Maestrelli, de 1967, que roda com carga geral e contêiner entre Guarulhos e o interior do Paraná; e da Translog, que opera apenas carga fármaco-hospitalar entre as suas 28 filiais de Mato Grosso do Sul e Santa Catarina.

O histórico papel de entroncamento viário exercido por Ponta Grossa remonta à época do tropeirismo do século XVIII, como o principal pouso das tropas nos campos gerais do Paraná antes da chegada à feira de Sorocaba. $\mathrm{A}$ cidade fica $113 \mathrm{~km}$ a noroeste de Curitiba pelas duplicadas BRs 277 e 376, um importante entroncamento viário e espécie de retroárea da RMC, com uma unidade do Sest/Senat e grande concentração de agentes dos circuitos inferior e superior.

Transportadora Primo, de 1969, que opera granel sólido e insumo para São Paulo e Minas; e Buturi, de 1966, que transporta insumo e carga geral para todo o Sul, São Paulo, Minas, Goiás e Bahia, estão entre as mais tradicionais do Estado. A Costa Texeira carrega insumo industrial e agrícola para 11 filiais, sendo seis em São Paulo e o restante em Santa Catarina, Paraná, Minas, Goiás e Pernambuco. A Del Pozo trabalha com combustível e granel sólido entre as regiões Sul, Sudeste e Centro-Oeste; mesmo tipo de carga da Vantroba, com filiais de Santa Catarina ao Rio de Janeiro e Pernambuco.

A Grycamp transporta granel sólido e químicos entre São Paulo, Minas e Goiás e a Novamel carrega estruturas metálicas. A Log-Sul movimenta granel agrícola sólido e líquido de São Paulo, Mato Grosso do Sul e Santa Catarina para Paranaguá e a Gamper, de 1978, opera carga geral e insumos em fluxos T1/B 
para São Paulo. Em Palmeira, no entroncamento da BR-277 com a PR-151, fica a Mastercargo, que transporta veículos, contêiner e carga geral para São Paulo.

A cidade também se destaca no transporte dos circuitos produtivos do agronegócio, pois sedia unidades de beneficiamento de soja (Cargill, Bunge e Louis Dreyfus), unidades misturadoras de adubo (Bunge e Louis Dreyfus) e um frigorífico da BRF (a vizinha Carambeí possui outros dois). Três empresas operam granel sólido agrícola (grãos e insumos): Rodoprince, para CentroOeste, São Paulo, Minas, Bahia, Sergipe e Alagoas; Larafran, de Paranaguá ao Centro-Oeste; e Boa Viagem, entre Santa Catarina, Sudeste e Goiás.

Na direção norte da PR-151, toda duplicada até Piraí do Sul, e saída para o sudoeste paulista (Itararé, Itapeva e Capão Bonito) e BR-153 (eixo viário de acesso ao Triângulo Mineiro, Goiás, Tocantins e Pará pelo interior paulista, a partir de Ourinhos), está o polo de papel e celulose do Estado, com produção de papel de impressão, imprensa, cartão, para fins sanitários e embalagens (cerca de $21 \%$ da capacidade produtiva nacional), e de produtos agroindustriais lácteos (Castrolanda e Batavo), com grande fluxo de carretas.

A Transardo, de Carambeí, opera fluxos T1 de carga geral e refrigerada para São Paulo, Minas, Bahia e Pernambuco, e em Castro fica a Log Brasil. Os postos Menegatti e Contorno, na PR-151, em Carambeí, são os principais pontos de agenciamento de carga.

Seguindo pela BR-376 no rumo norte a partir de Ponta Grossa, alcançase o eixo nodal Maringá-Londrina, cuja elevada geração de carga referente ao agronegócio e a força industrial do eixo garantem o nexo territorial com Cascavel, Ponta Grossa, Curitiba, Paranaguá, Mato Grosso, Mato Grosso do Sul e São Paulo, suficiente para justificá-lo.

O caminho para Paranaguá é pelos $98 \mathrm{~km}$ duplicados da BR-277, na descida da Serra do Mar. Tido com um dos maiores gargalos infraestruturais do país, o acesso ao porto tem enfrentado situações complicadas principalmente no verão, época do pico da safra de grãos do Centro-Oeste e das viagens a turismo pelas praias paranaenses. As filas de carretas carregadas de soja aguardando autorização para entrada no porto, no acostamento da BR-277, já chegou até Curitiba. A lei 11.442/07 prevê espera para carga e descarga de até 
cinco horas, e após esse período há uma taxa de $\mathrm{R} \$ 1$ por tonelada a cada hora de atraso, paga pelo embarcador a ETC ou TAC que efetuou o serviço.

Ocorre que a demora é atribuída ao caminhoneiro e o pagamento da taxa não é cumprido. É a prática do caminhão-silo, como explicou Claudinei Pelegrini, da Abcam. "Os grandes despachantes, que mandam mercadoria para fora do país e utilizam os caminhões para chegar até os portos, usam as carretas para ser um depósito e não querem pagar a estadia do caminhão." 0 problema não é portuário, mas de silagem e regularização do fluxo a partir das áreas produtoras (HUERTAS, 2013).

Da capital partem eixos viários de grande importância para ligações interregionais e internacionais. A BR-116 (FOTOS 1-2) é a única ligação direta de toda a Região Sul com a RMSP e Estados do Rio de Janeiro, Espírito Santo e Nordeste. Chamada de Régis Bittencourt no trecho de $408 \mathrm{~km}$ entre as capitais paranaense e paulista, é uma estrada que atravessa topografia bastante irregular com uma engenharia antiga, o que significa ausência de túneis nas serras e curvas fechadas.

Duplicada do Paraná até Miracatu (SP), foi concedida em 2008 à empresa espanhola OHL, que venceu a licitação com deságio de 49,2\% no valor da tarifa básica de pedágio $(R \$ 2,685)^{2}$. A duplicação da Serra do Cafezal, entre Miracatu e Juquitiba (19 km), tem esbarrado em questões ambientais e atrasos por parte da concessionária, trecho que talvez seja um dos maiores gargalos rodoviários de todo o país por conta do tráfego pesado em pista de traçado geométrico antigo e inadequado. "Na Régis Bittencourt não dá para cumprir prazos", confirmou Antonio Valdivia Neto, assessor técnico da Associação Nacional do Transporte de Cargas e Logística (NTC\&Logística) ${ }^{3}$. No final de 2012 foi liberada a licença ambiental para a realização da obra, que se encontra em andamento.

A BR-476 parte na direção sudoeste como um dos principais eixos para São Borja e Uruguaiana, na fronteira gaúcha com a Argentina. A estrada acaba na BR-153 e segue cruzando Santa Catarina (FOTO 3) e o interior gaúcho até

\footnotetext{
${ }^{1}$ In <www.portalntc.org.br/index.php?option=content\&view=ar> Acesso em: 15.out.2012.

${ }^{2}$ Em 2012, a venda da OHL para a espanhola Abertis (51\%) e a estadunidense Brookfield Motorways (49\%) gerou a Arteris.

${ }^{3}$ Entrevista concedida em São Paulo em 31 de março de 2011.
} 
HUERTAS, D. M.

DINÂMICAS TERRITORIAIS DOS PRINCIPAIS NODAIS SULISTAS DO TRANSPORTE RODOVIÁRIO DE CARGA

Passo Fundo, onde se encontra com a BR-285. Daí pega o rumo oeste até São Borja, no entroncamento com a BR-472. Por esta rota, muito utilizada pelos fluxos com destino aos países vizinhos pelas ETCs do Sudeste e do Paraná, são 1.118 km de Curitiba a Uruguaiana.

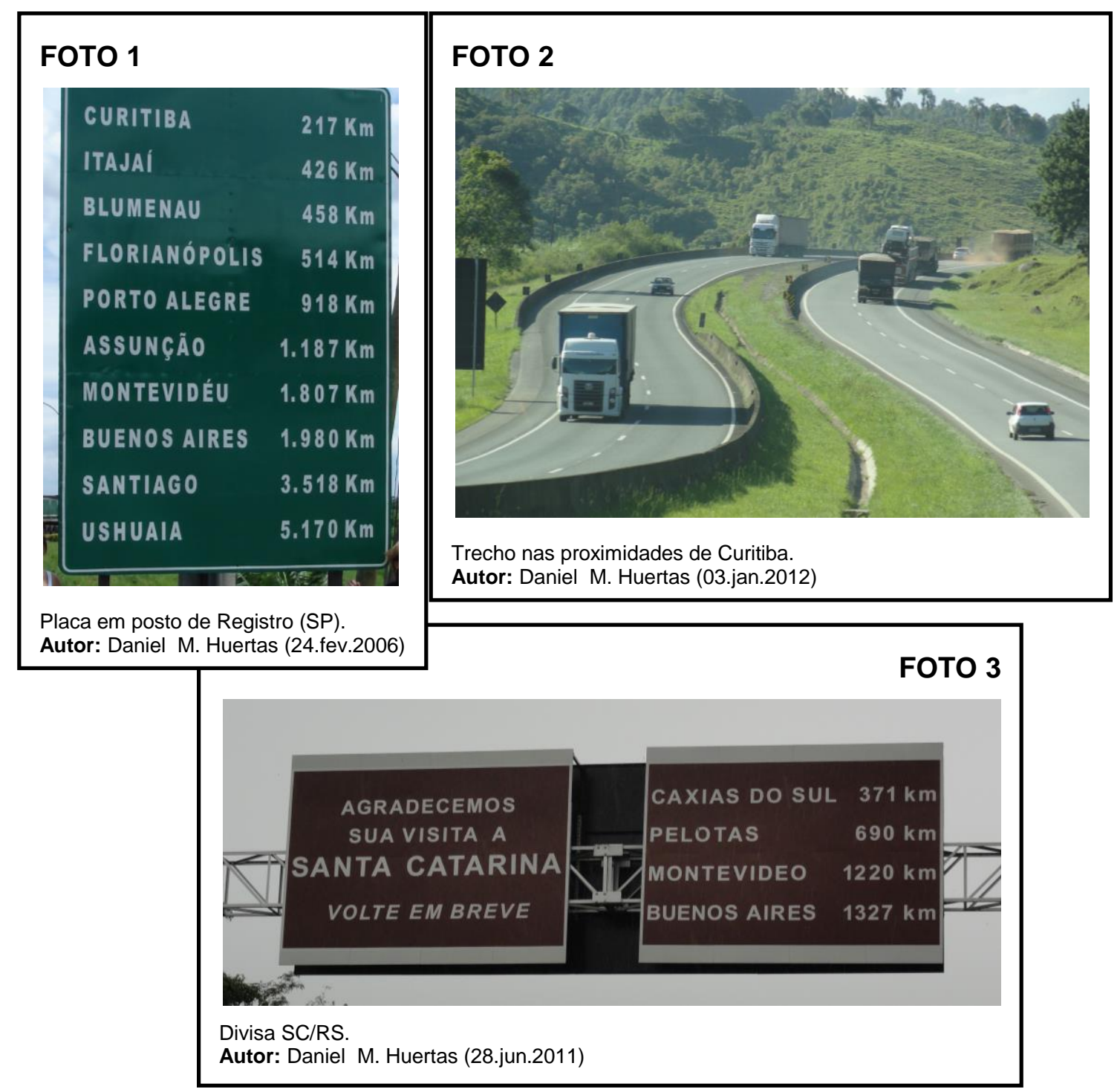

De Curitiba, descendo a serra, são 92 km duplicados pela BR-376 até Garuva, onde começa o eixo catarinense (DIAGRAMAS 2-3). Este ponto marca o reinício da BR-101 - a principal via longitudinal que acompanha o litoral brasileiro de São José do Norte (RS) a Touros (RN) não foi construída no Paraná e no litoral sul de São Paulo -, totalmente duplicada até Osório (RS).

O eixo estende-se ao longo da BR-101 de Garuva a Araranguá (FOTOS 4-5), com pequenos prolongamentos no sentido oeste para alcançar 
importantes centros industriais do Estado, como Criciúma, Orleans e Içara (embalagens plásticas, implementos rodoviários e revestimentos cerâmicos), São João Batista (polo calçadista), Brusque e Blumenau (complexo têxtil) e Jaraguá do Sul (polo eletro-metalmecânico e fabril). Os terminais de carregamento de combustível estão em Guaramirim, Itajaí e Biguaçu e os portos secos localizam-se em São Francisco do Sul e Itajaí - esta cidade ainda sedia um Clia. As unidades do Sest/Senat ficam em Blumenau, Itajaí, Joinville, Florianópolis e Criciúma.

Uma particularidade da divisão territorial do trabalho em Santa Catarina é a forte sinergia intermodal com um conjunto portuário que tem recebido constantes investimentos em ampliação e melhorias no acesso rodoviário. Outro ponto a ser levantado é o fato de que a setorização produtiva regional de certa forma condicionou o transportador, que acabou se especializando em nichos específicos de carga. Essa questão, entretanto, favoreceu um histórico de briga com o embarcador que acabou fortalecendo o TRC no modelo cooperativado, caso único no país.

"Aqui realmente é uma federação pelo sincronismo com os sindicatos, existe uma única voz no Estado", comentou Leonardo de Carvalho, diretor executivo da Federação das Empresas de Transporte de Carga e Logística no Estado de Santa Catarina (Fetrancesc) ${ }^{4}$, que implantou um sistema eletrônico para que todos os CT-es das ETCs associadas sejam emitidos nos sindicatos, reduzindo o custo operacional na emissão de documentos fiscais. Em 2008 o órgão também montou uma empresa para estudar a fundo o custo/benefício do pedágio e disputar o leilão da BR-101 norte, com proposta de $\mathrm{R} \$ 1,65$, vencido pela espanhola OHL.

\footnotetext{
${ }^{4}$ Entrevista concedida em Florianópolis em 08 de julho de 2011.
} 
DIAGRAMA 2. Configuração territorial do eixo catarinense (Garuva-Tijucas)

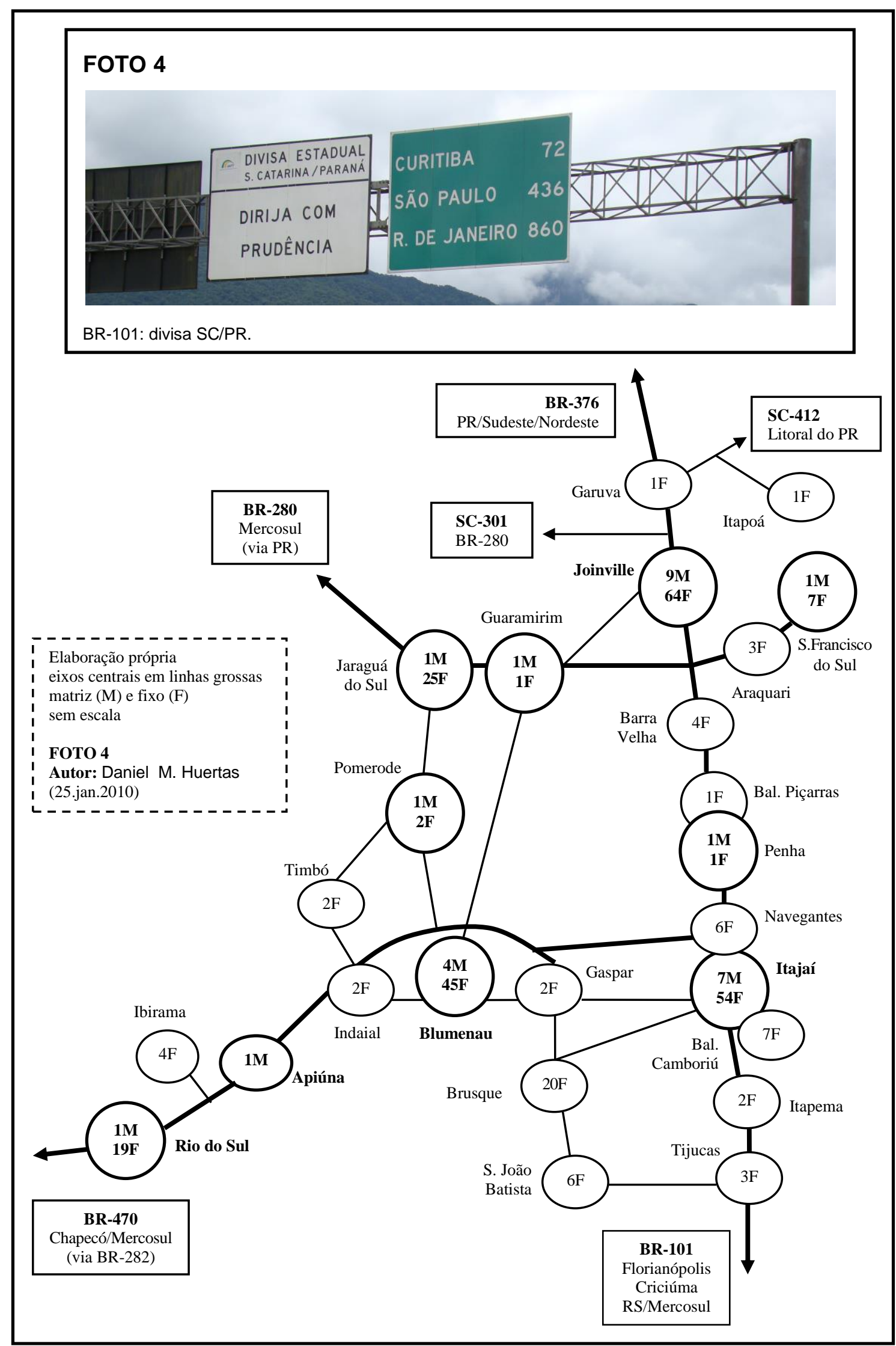

R. Ra'e Ga - Curitiba, v. 37, p. $160-189$, Ago/2016 


\section{DIAGRAMA 3. Configuração territorial do eixo catarinense}

\section{(Tijucas-Araranguá)}

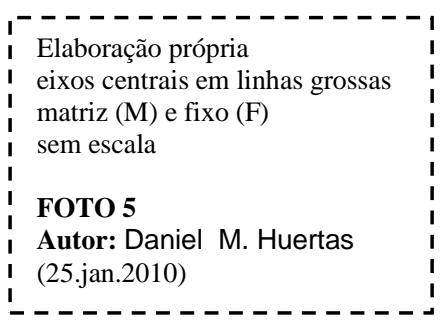

eixos centrais em linhas grossas

matriz (M) e fixo (F)

sem escala

FOTO 5

Autor: Daniel M. Huertas

(25.jan.2010)

I - - - - - - - - - - I

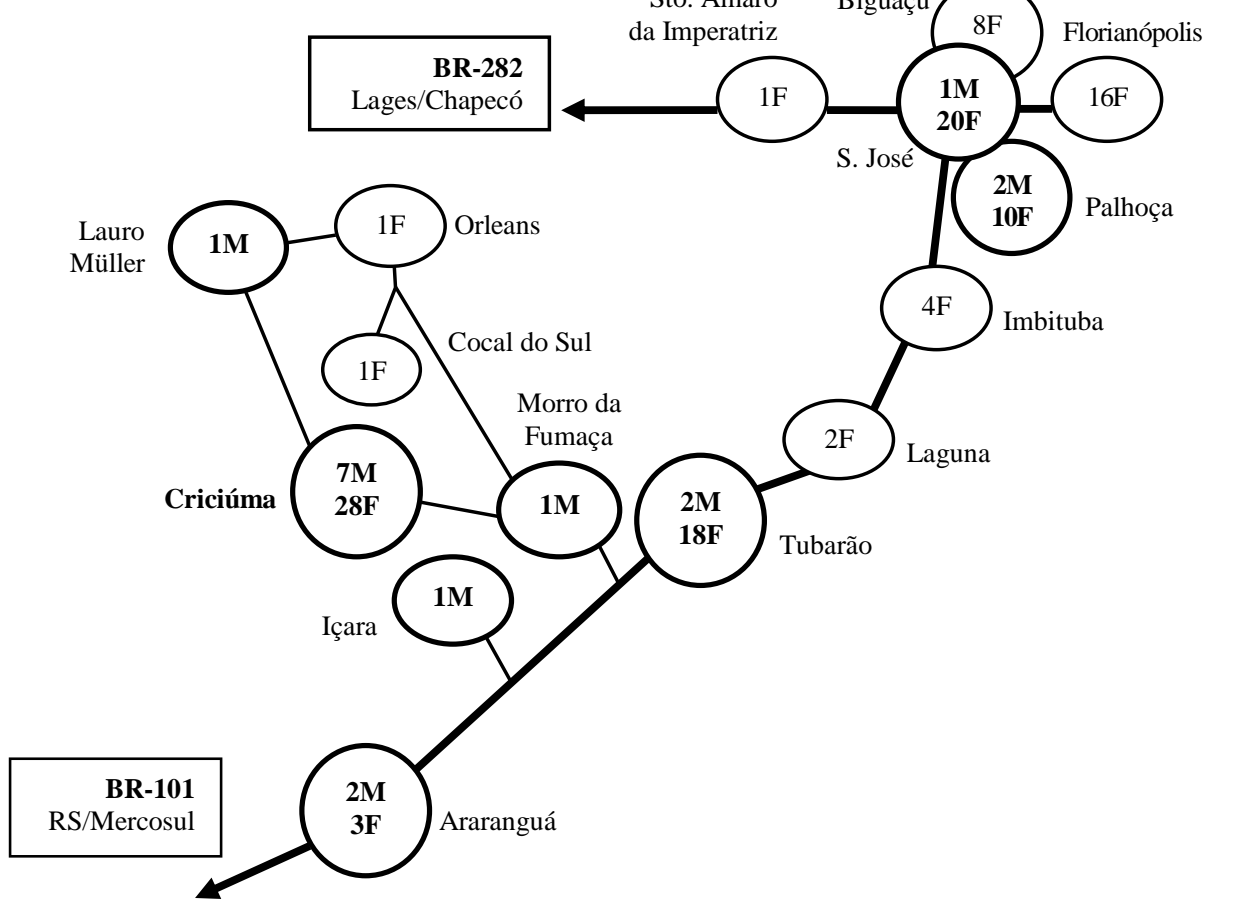

Sto. Amaro da Imperatriz

\section{FOTO 5}

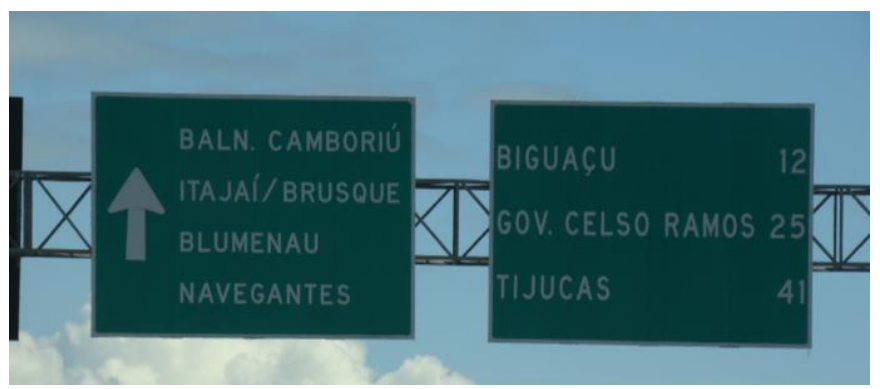

BR-101: próximo ao trevo de acesso a Florianópolis 
A nova investida da federação catarinense é implantar o primeiro centro de apoio de cargas perigosas do Brasil. A Dalçoquio, umas das transportadoras mais tradicionais (1968) e relevantes do TRC catarinense, cederia em comodato para a Fetrancesc, por 23 anos, uma área de $20 \mathrm{mil} \mathrm{m}^{2}$ anexa ao Posto Santa Rosa (BR-101), em Itajaí, onde também funciona um dos principais pontos de agenciamento de carga de todo o eixo.

A responsabilidade sobre a construção do centro ficaria a cargo da $\mathrm{OHL}$, que como contrapartida poderia receber a prorrogação da concessão de exploração da BR-101. A ideia é que o centro seja um modelo a ser implantado a cada $300 \mathrm{~km}$ nas futuras concessões, sobretudo após a aprovação da lei 12.619/13, que exige paradas em tempos determinados. Uma parte do centro ficaria reservada como área de serviços, administrada pela Fetrancesc.

Na porção norte do eixo catarinense há um conjunto expressivo de ETCs locais. Em Joinville, estão Coopercargo, Boa Vista e Mann, que operam carga geral e insumo industrial em fluxos T1 respectivamente para São Paulo e Nordeste; São Paulo e de Santa Catarina ao Maranhã e Pará. Apenas carga geral fica a cargo da Transville, para Paraná e São Paulo; Transoliveira, com 21 filiais do Paraná ao Tocantins; e Gelsleither. Rodocargas, de carga alimentícia, e Manchester (1972), de insumo industrial, completam o quadro.

Itajaí está se tornando um dos maiores centros logísticos do país, com investimentos constantes em fixos operacionais de transportadores e embarcadores. Cabe ressaltar que o porto da cidade também se beneficiou em larga escala da chamada "guerra dos portos" - as importações no Estado cresceram de US $\$ 5,75$ bi em 2009 para US $\$ 12,38$ bi em $2011^{5}$-, explicada no eixo capixaba. Desta porção do litoral catarinense é originada boa parte da carga estadual de pescados (a primeira colocada na produção nacional de pesca industrial, com cerca de 150 mil t), que segue para toda a Região Sul, São Paulo e Minas Gerais por via rodoviária, em carretas frigorificadas.

Além de Itajaí, que em 2011 movimentou cerca de 438 mil teus, outros três portos se destacam na porção norte do Estado, originando carga para o TRC: Navegantes (na margem oposta do Rio Itajaí-Açu), São Francisco do Sul

\footnotetext{
${ }^{5}$ In revista Transporte Moderno, ano 49, $\mathrm{n}^{\mathrm{o}}$ 451, jan-fev.2012, p.72.
} 
e o recém-inaugurado terminal de uso privativo em Itapoá, especializado em contêiner refrigerado (refeer), que ampliará a sua capacidade de movimentação de 500 mil teus por ano para 2 milhões. A montadora alemã BMW implantou uma fábrica em Araquari, e em São Francisco do Sul e Penha ficam a sede da Zport e Bendini, que movimentam respectivamente contêiner e granel sólido e carga geral e insumo.

Em Itajaí está a sede da Dalçoquio, de 1968, uma das transportadoras mais tradicionais e respeitadas do Estado, operando combustível, insumo, carga geral e químicos entre 28 filiais que englobam as regiões Sul, Sudeste e CentoOeste e a Bahia. A Cootravale transporta contêiner, carga frigorificada e granel sólido e atende 27 filiais no Sul e Sudeste, Goiás, Mato Grosso, Bahia, Pernambuco e Ceará. A Vatlog trabalha com carga geral em fluxos T1 para São Paulo e Espírito Santo. Insumo industrial é a especialidade de SAG LOG, San Martino e Transpezzini, e a DC opera carga de trânsito aduaneiro, granéis líquidos e gases industriais do Rio Grande do Sul ao Espírito Santo e a Manaus.

Em Blumenau, a $45 \mathrm{~km}$ pela movimentada BR-470 ou pela paralela SC470, via Ilhota, Ociani e MTR operam carga geral respectivamente para São Paulo, Rio, Goiás e Distrito Federal e Região Sul, São Paulo e Minas. A Nasul Cargo, de 1973, atende apenas o polo local de confecções, e a Cajumar transporta carga geral e química em fluxos T1/B para São Paulo, Paraná e Espírito Santo e T1/C para o resto do Estado. Seguindo pela BR-470 ficam a Transportes Apiúna, da cidade homônima, e Mirin do Sul, de Rio do Sul.

$\mathrm{Na}$ vizinha Pomerode está a Ramthun, de 1958, uma das ETCs catarinenses mais antigas de carga geral. Apesar de atender toda a Região Sul, São Paulo e Minas, o seu foco está no Nordeste, com 17 de suas 28 filiais (PE/4, MA/3, BA/2, PB/2, CE/2, SE/1, AL/1, RN/1 e PI/1). A Transmagna, de Guaramirim, transporta contêiner e carga geral do Paraná ao Rio de Janeiro, além de intensos fluxos T2 em Santa Catarina, onde estão 14 de suas 26 filiais. Em Jaraguá do Sul está sediada a Transligue, de carga geral e trânsito aduaneiro na rota Joinville-São Paulo.

$\mathrm{Na}$ porção central do eixo catarinense está a Região Metropolitana de Florianópolis (RMF), com concentração de 65 fixos de ETCs locais e de outros 
Estados (SP/19, SC/16, RS/12, PR/7, MG/3, PE/3, ES/2, TO/1, GO/1, MT/1 e $\mathrm{CE} / 1$ ). Interessante notar que a maioria dos fixos situam-se em Biguaçu, São José e Palhoça, na área continental da RMF. Os fluxos Florianópolis $\leftrightarrow$ São Paulo e Florianópolis $\leftrightarrow$ Rio de Janeiro, segundo a Fetrancesc, são os principais interestaduais. Em Palhoça estão Transacácio, especializada no transporte náutico (embarcações de médio e pequeno porte), e Connect, de equipamentos de telecomunicação e filial em São Paulo. Em São José fica a Albertoni, de carga geral e confecções (cabideiro).

Descendo a BR-101 sentido Porto Alegre, alcançamos o núcleo sul do eixo. Em Tubarão, cidade a $138 \mathrm{~km}$ da capital e próxima ao Porto de Imbituba, estão Transzape, de carga geral, que atende São Paulo, Minas, Bahia e Pernambuco; e Lima, de 1972, que transporta granel sólido para cimenteiras. Em Criciúma, Transportes Natal, Fluorita, Destak e Ouro Negro operam carga geral (a penúltima em fluxos T1 até o Rio de Janeiro e a última, com 14 filiais no Estado, em fluxos T1 no Sul, São Paulo e Rio Grande do Sul), e a Francisconi transporta insumos e carga geral para São Paulo e Espírito Santo. Manosso e Translara carregam carga geral e contêiner (a última também transporta insumos para a indústria local de cerâmica).

A T-Dago, da vizinha Içara, opera carga geral, insumo, contêiner e carga siderúrgica para São Paulo, Espírito Santo, Goiás, Bahia e Pernambuco. Em Morro da Fumaça a Salvan trabalha em toda a Região Sul e São Paulo com insumo e carga química; a Fontanella, de Lauro Müller, transporta insumo e produto acabado das indústrias de revestimento cerâmico (Eliane, Pierini e Portinari) para São Paulo, Goiás, Bahia, Pernambuco, Paraíba e Ceará. Em Araranguá, a 55 km da divisa com o Rio Grande do Sul, ficam a Irmãos Darolt, de granel sólido agrícola, e a TKE, que opera carga siderúrgica e granel sólido para Rio Grande do Sul, Minas e Espírito Santo.

No Rio Grande do Sul a BR-101 encontra-se duplicada até Osório, no entroncamento com a BR-290 (conhecida como Freeway), início do polígono gaúcho, composto pela Região Metropolitana de Porto Alegre (RMPA) e prolongamentos a Caxias do Sul (norte), Serafina Correa (noroeste), LajeadoSanta Cruz do Sul (oeste) e Osório (leste) (DIAGRAMA 4). A RMPA é o 
epicentro do nodal, com terminal de carregamento de combustível em Canoas, portos secos em Novo Hamburgo, Canoas e Caxias do Sul e unidades do Sest/Senat em Bento Gonçalves, Caxias do Sul, Lajeado e Porto Alegre.

Outro destaque do nodal é a forte ocorrência da intermodalidade. A Brado possui terminais rodoferroviários em Esteio, Triunfo e Porto Alegre, com clientes de peso como Trasmontina, Dambroz e Mercur. O complexo portuário fluviomarítimo é encabeçado pelo porto da capital e engloba os portos de Estrela, Charqueadas e Pelotas, que se conectam ao Porto de Rio Grande, no sul do Estado, pelas hidrovias lacustres (Guaíba e dos Patos), rios Jacuí, Taquari, Caí, Sinos, Gravataí e canal de São Gonçalo. Carvão mineral, produtos siderúrgicos, grãos, carnes, bobinas de papel, insumos agrícolas, sal, celulose e transformadores elétricos estão entre os produtos mais movimentados neste sistema, que depende do caminhão nos fluxos T2.

No corredor RMPA-Serra Gaúcha está o principal centro industrial do Estado (FOTOS 6-7), com destaque para a produção calçadista (Novo Hamburgo, São Leopoldo e Parobé), petroquímica (Triunfo e Canoas), automobilística (fábrica da GM em Gravataí; de caminhões e tratores Agrale e caminhões International em Caxias do Sul; e de tratores Massey Fergusson em Canoas), siderúrgica (Sapucaia do Sul), moveleira (Bento Gonçalves, com 340 fábricas), metalmecânica e implementos rodoviários (Caxias do Sul), entre outras.

O fluxo entre a capital e Caxias do Sul está entre os mais densos do Estado, e existem duas rotas: pela BR-116 (137 km), mais antiga, com curvas fechadas e duplicada apenas até Novo Hamburgo; e pelas RSs 122 e 452 (129 $\mathrm{km})$, duplicada até Bom Princípio, na subida da serra. O trecho duplicado de 18 km entre Caxias do Sul e Farroupilha, pela RS-122, também é bastante intenso.

Para Curitiba e São Paulo, principais fluxos interregionais, as transportadoras preferem o caminho pelo litoral, acessado da RMPA pela BR290 ou de Caxias do Sul pela RS-453, a "Rota do Sol". Direto pela BR-116, via Vacaria (RS) e Lages (SC), com alternativa pela RS-122 por Antônio Prado, é a rota preferencial dos carreteiros. A pequena cidade de São Marcos, de pouco mais de 19 mil habitantes e a $39 \mathrm{~km}$ ao norte de Caxias do Sul pela BR-116, é considerada a cidade-símbolo do caminhoneiro no Brasil. 


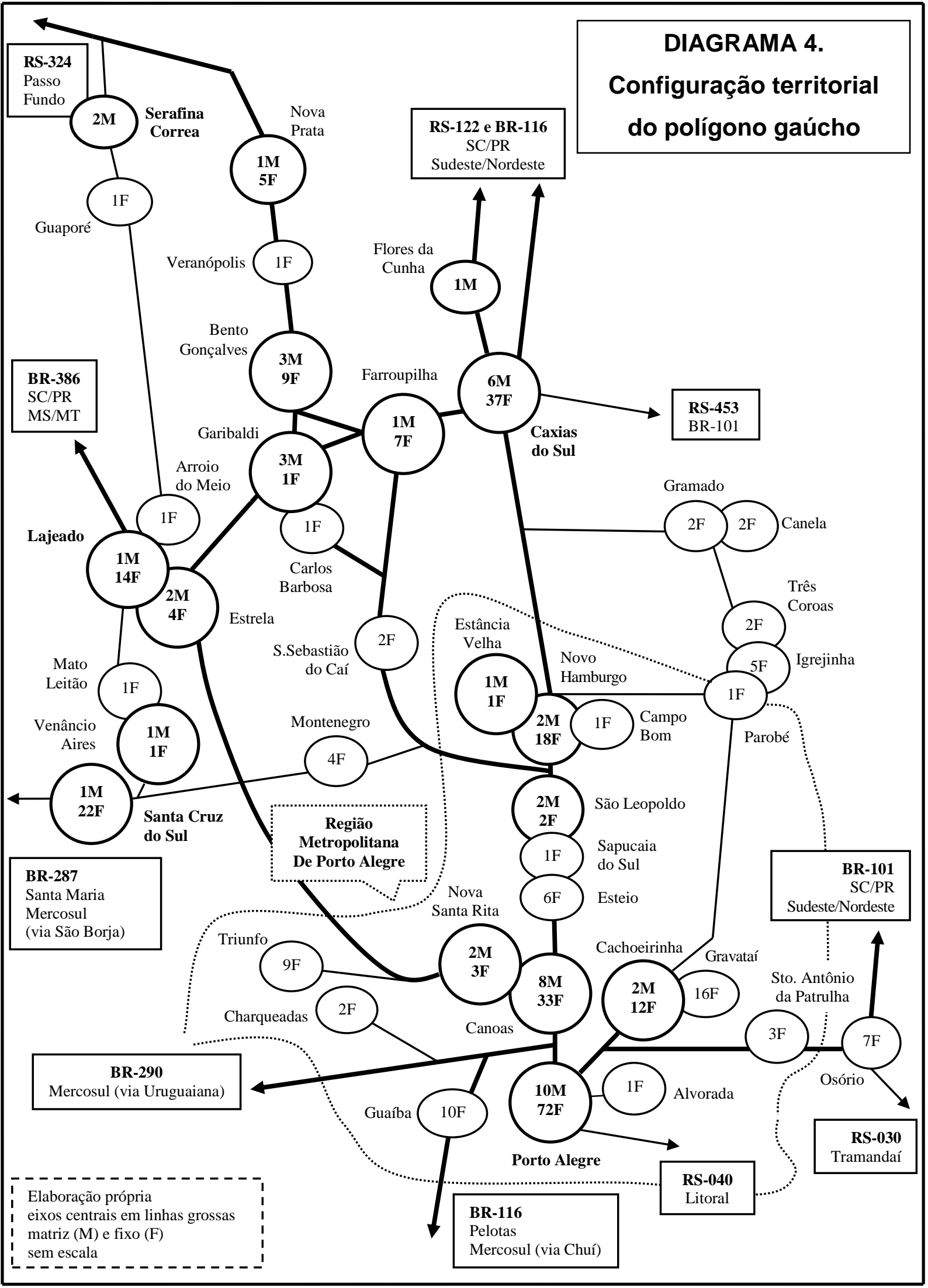




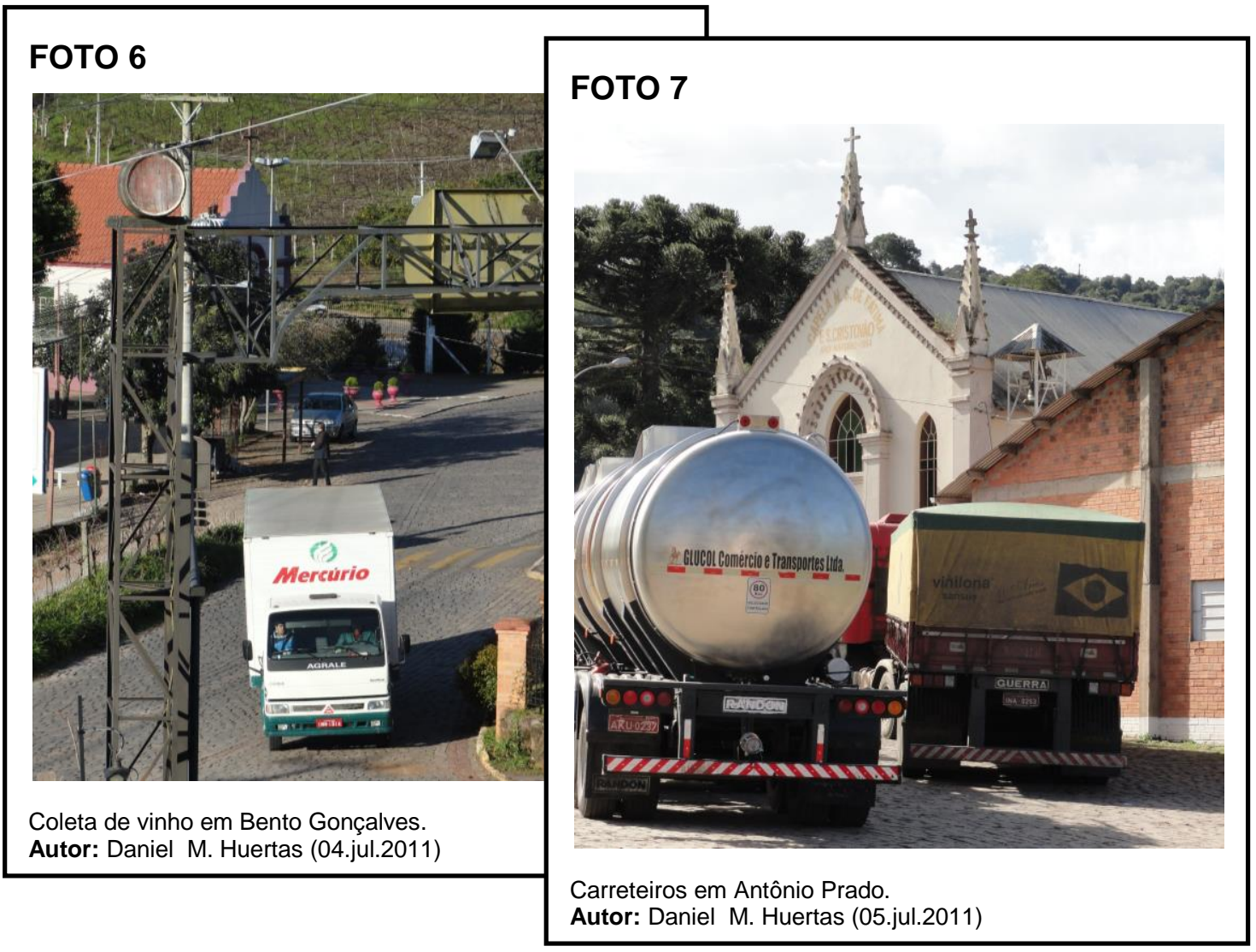

É considerável a concentração de ETCs do circuito superior nas cidades da Serra Gaúcha, polarizada por Caxias do Sul, berço de dois gigantes do circuito industrial de implementos rodoviários: Randon e Guerra. A Transcaxias trabalha com autopeças, químicos e insumo industrial em todo o Sul e São Paulo. A Servicarga, com filiais em Duque de Caxias, Curitiba e São Bernardo, transporta autopeças e chassis de ônibus da Marcopolo.

A cidade ainda é sede da Translovato, que com 90 filiais atende carga geral para toda a Região Sul (RS/29, SC/14 e PR/16), São Paulo (19) e Minas Gerais (12) em fluxos T1 e T2. A Irapuru, também de carga geral, opera nas regiões Sul e Sudeste, Goiás e Distrito Federal; e a Bedin (Transpanex), de 1953, trabalha com insumo e carga geral nos Estados do sul, São Paulo, Rio e Minas. Kalinca, de carga geral, completa o quadro.

Farroupilha abriga a Plimor, uma das maiores do Estado, com 70 filiais em fluxos T1 e T2 até São Paulo. Em Bento Gonçalves estão TBB, que transporta carga geral para Santa Catarina, eixo da Belém-Brasília e Piauí; Ravanello, que opera carga geral de Santa Catarina a Rondônia, via Centro- 
Oeste; e Rasador, de móveis, carga geral e insumo industrial entre Porto Alegre, Curitiba e Barueri.

$\mathrm{Na}$ vizinha Garibaldi estão Biano, de carga geral e foco em fluxos T1 para Alagoas, Pernambuco e Paraíba; Sul Nativa, de carga geral; e Rodoseni, de granel agrícola. Em Flores da Cunha, na RS-122, está sediada a Rodomio, especializada no carregamento de insumo para a indústria de bebidas. No rumo de Passo Fundo pela RS-470, em Nova Prata, fica a Unius. Na mesma direção, mas pela RS-129, a Cadore, de 1964, tem sede em Serafina Correa e opera fluxos T1 e T2 de carga geral com Paraná e São Paulo. Na mesma cidade está a Serrafrio, de 1972, especializada no transporte de carga refrigerada com filial em Taboão da Serra (SP).

Fora do nodal, seguindo pela BR-116, ficam em Vacaria a Cavalinho, de carga petroquímica, granel líquido químico e bebidas para São Paulo, Rio e Bahia; a Schio, comprada pela paulista Júlio Simões, que opera carga geral, refrigerada, insumo e químicos para as regiões Sul e Sudeste, Goiás, Bahia, Alagoas, Pernambuco, Pará e Amazonas; e a Transportadora Rocha, que movimenta carga geral, química e especial para o interior do Estado, Santa Catarina, Paraná, Minas Gerais e Ceará.

Em Porto Alegre há uma concentração de empresas dos circuitos inferior e superior no bairro Porto Seco, próximo da saída para a BR-116. A Minuano opera carga geral na Região Sul, São Paulo e Rio; e a Vitória para os Estados sulistas, São Paulo, Minas, Goiás, Bahia, Ceará, Rondônia, Pará e Amazonas, trabalhando com fluxos T2 em alguns deles. A Raupp, com filiais de Santa Catarina ao Rio, é especializada no transporte de carga têxtil, e a Gabardo carrega veículos para todo o Sul e Sudeste, Goiás, Bahia e Ceará.

A Einchenberg opera trânsito aduaneiro e insumo em toda a região Sul, São Paulo, Bahia e Amazonas. A Mercúrio, uma das ETCs mais tradicionais da capital, foi comprada pela TNT. A empresa conta com 73 filiais nas regiões Sul, Sudeste e Nordeste (RS/13, SP/12, SC/9, PR/8, MG/8, RJ/4, BA/4, ES/3, CE/3, $\mathrm{PE} / 2, \mathrm{SE} / 1, \mathrm{AL} / 1, \mathrm{~PB} / 1, \mathrm{RN} / 1, \mathrm{Pl} / 1$ e MA/1) para atendimento de fluxos T1 e T2. A Troca movimenta carga geral e insumo industrial para São Paulo e a 
Transadubo carrega granéis sólidos agrícolas em fluxos T1 para Paraná, São Paulo, Minas Gerais, Espírito Santo e Goiás.

Em Canoas estão três das mais tradicionais empresas do Estado: Henrique Stefani, de 1954, que transporta combustível e carga química entre Paraná, São Paulo, Rio, Espírito Santo e Bahia; Panazzolo, de 1963, que opera carga geral e insumo em fluxos T2 para as oito filiais no Estado e fluxos T1 para Santa Catarina, Paraná e Região Sudeste; e Translíquidos, de 1966, que movimenta combustível e petroquímicos.

A Transpaulo, de carga geral e insumo, conta com 64 filiais pelo país (RS/14, SC/15, PR/7, SP/7, MG/5, MS/4, MT/3, RO/3, RJ/1, ES/1, GO/1, DF/1, $\mathrm{TO} / 1$ e AC/1). A Modular, de carga geral, trabalha com fluxos T1 para São Paulo, Rio, Espírito Santo, Bahia e Pernambuco, e fluxos T1 e T2 em toda a Região Sul. A Dalacorte, de 1980, opera insumo para construção civil, e a Silveira Gomes trabalha com carga geral, refrigerada e insumo industrial em fluxos T1 para todo o Sul, São Paulo, Minas Gerais e Goiás. A Mauá, com filial em São José (SC), é especializada em cargas sensíveis (médico-hospitalares, caixas eletrônicos, automoção industrial, robótica, periféricos, computadores e equipamentos de telecomunicações e telefonia celular).

A Transmiro, sediada em Cachoeirinha e fundada em 1958, opera carga geral, insumo, bebidas e carga siderúrgica, com filiais no Estado, Santa Catarina e São Paulo. Ainda na mesma cidade, a Hoff trabalha com carga especial. Em Estância Velha, a Transkinko transporta insumo e carga química. Em Nova Santa Rita, a Reiter carrega granel sólido agrícola e carga refrigerada para São Paulo e Goiás, e a GM LOG opera carga geral e química para Santa Catarina, São Paulo e Bahia.

Em São Leopoldo, a Spolier, de insumo, conta com 15 filiais em São Paulo (seis), Rio Grande do Sul, Paraná, Minas, Rio, Bahia e Pernambuco; e a Unidão, de 1969, opera carga geral e química para as regiões Sul e Sudeste. Na vizinha Novo Hamburgo, a Sirius atende trânsito aduaneiro entre as filiais de Rio Grande e Itapecerica da Serra (SP), e a Trasduarte, com 14 filiais em quatro Estados, é especializada no transporte de insumo para a indústria calçadista. 
No rumo da BR-386 (sentido Passo Fundo), que tem apenas $58 \mathrm{~km}$ duplicados até o entroncamento com a BR-287, ficam a sede da Transpa Giovanella e Tomasi, em Estrela. Na citada BR-287 estão a Transportadora Augusta, em Venâncio Aires, que tem filiais no Estado, Santa Catarina e São Paulo; e a VBR, em Santa Cruz do Sul, que opera contêiner para Rio de Janeiro e Bahia. Seguindo para o sul do Estado pela BR-116, são 258 km de intenso movimento até Pelotas, um dos principais fluxos intraestaduais.

O fato de estar situado em um dos extremos do país, a grandes distâncias do restante do território nacional, não gerou vantagens competitivas para o TRC gaúcho, como constatou Paulo Vicente Caleffi, presidente da Federação das Empresas de Logística e Transporte de Cargas do Rio Grande do Sul (Fetransul), mas a aliança do espírito familiar e empreendedor com o conhecimento empírico ("conhecimento da boleia") ajudou no desenvolvimento do carreteiro e, posteriormente, de grandes empresas transportadoras. A organização do setor também pode ser constatada em todo o Estado, com 10 sindicatos que "vivenciam os interesses regionais das Empresas", como diz um calendário promocional da entidade. "Cabe à Fetransul fortalecer os sindicatos porque o empresário precisa se organizar, e devemos levar a informação para o interior", alegou Caleffi 6 .

\section{CONSIDERAÇÕES FINAIS}

Os três Estados sulistas formam um denso corredor rodoviário longitudinal de cerca de $700 \mathrm{~km}$ entre Curitiba e Porto Alegre, seja pelo litoral (BRs 376, 101 e 290), seja pelo interior (BR-116). A pesquisa apontou que a ligação entre as capitais do Paraná e Rio Grande do Sul está entre os principais fluxos interestaduais para ambos os Estados, além da relação com São Paulo. É explícita a densidade de ETCs que operam carga fechada de insumo industrial e carga geral para todas as regiões do Brasil, fato que denota a importância do setor industrial na economia, embora seja bastante diversificada a composição empresarial do TRC no Sul do país.

\footnotetext{
${ }^{6}$ Entrevista concedida em Bento Gonçalves (RS) em 4 de julho de 2011.
} 
A grande quantidade de autônomos sulistas que roda o país é resultado em grande parte da divisão territorial do trabalho. Como afirmou o caminhoneiro autônomo paulista Marcos Aparecido Izelli, que frequenta o Terminal de Cargas Fernão Dias, na capital paulista, "os carreteiros do sul vêm vazio e praticamente moram em São Paulo, pois chegam a ficar até um ano sem voltar para casa"7.

Em termos de frete-retorno também há mais equilíbrio nas relações interestaduais que envolvem o corredor Curitiba-Porto Alegre, que mantêm fluxos densos e constantes com o interior dos três Estados. Esta, inclusive, talvez seja a particularidade mais marcante do TRC no sul do país: a força que adquiriu no interior, tanto em fluxos T1 quanto T2. Os dados coletados nas pesquisas de campo apontam que as federações do Paraná e Santa Catarina possuem respectivamente $75,4 \%$ e $92,1 \%$ de seus associados no interior.

\section{REFERÊNCIAS BIBLIOGRÁFICAS}

ARROYO, M. Dinâmica territorial, circulação e cidades médias. In: SPOSITO, E. S.; SPOSITO, M. E. B. e SOBARZO, Oscar (orgs.). Cidades médias: produção do espaço urbano e regional. São Paulo: Expressão Popular, 2006, p.71-85.

- La división territorial del trabajo: un proceso e una categoría para intepretar el mundo. In: CONFERÊNCIA INTERNACIONAL DE GEOGRAFIA CRÍTICA, 4aㅗ , 2005, Ciudad de México: anais eletrônicos, p.1-12.

CLOZIER, R. Géographie de la circulation. Paris: Génin, 1963.

CORRÊA, R. L. Interações espaciais. In: CASTRO, I. E. de; GOMES, P. C. da C. e CORRÊA, R. L. (orgs.). Explorações geográficas: percursos no fim do século. Rio de Janeiro: Bertrand Brasil, 1997, p.279-318.

\footnotetext{
${ }^{7}$ Entrevista concedida em São Paulo em 28 de dezembro de 2011.
} 
HUERTAS, D. M. Território e circulação: transporte rodoviário de carga no Brasil. 2013. Tese de Doutorado em Geografia Humana, Departamento de Geografia, Universidade de São Paulo, São Paulo.

MARX, K. O capital: crítica da economia política - Livro Segundo: 0 processo de circulação do capital, volume III. 13.ed. Rio de Janeiro: Civilização Brasileira, 2011 [1893].

RAFFESTIN, C. (1980). Por uma geografia do poder. São Paulo: Ática, 1993.

SANTOS, M. (1979). O espaço dividido: os dois circuitos da economia urbana dos países subdesenvolvidos. $2^{\underline{a}}$ ed. $1^{1 \underline{a}}$ reimp. São Paulo: Edusp, 2008.

(1993). A urbanização brasileira. 5.ed. São Paulo: Edusp, 2005.

(1996). A natureza do espaço. Técnica e tempo. Razão e emoção. 4.ed. São Paulo: Edusp, 2004.

(1979). Economia espacial: críticas e alternativas. 2.ed. São Paulo: Edusp, 2003.

Metamorfoses do espaço habitado. São Paulo: Hucitec, 1988.

SAVY, M. Logistique et territoire. Espace géographique, Paris, tome 22, ํㅡ 3 , p.210-18, 1993.

SILVA JUNIOR, R. F. Geografia de redes e da logística no transporte rodoviário de cargas: fluxos e mobilidade geográfica do capital. 2004. Dissertação de Mestrado em Geografia, Universidade Estadual Paulista (Unesp), Presidente Prudente.

THOMSON, J. M. Teoría económica del transporte. Madrid: Alianza Editorial, 1976. 